\title{
Flow Striations on Friction Stir Welded Aluminum
}

\author{
J.C. McClure, S. Aloor, L.E. Murr \\ Metallurgical and Materials Engineering Department, University of Texas El Paso
}

Friction Stir Welding is a relatively new welding process $\left[{ }^{1}\right]$ which has been most widely applied to butt welding aluminum alloys. There has been some recent success in welding steel $\left[{ }^{2}\right]$ and even aluminum/aluminum oxide composites $\left[{ }^{3}\right]$. In this process the work piece is firmly clamped to a backing plate and a rotating threaded pin tool is plunged into the work piece along the faying surface. The length and diameter of the pin tool is approximately the same as the thickness of the work piece. The pin tool is mounted in a wider shoulder which, after plunge, presses against the work piece and heats the work piece by a combination of friction between the shoulder and the work piece and by plastic deformation of material as its moves around the pin tool. As the pin tool is advanced along the faying surface, material is swept around the pin tool and forms a weld in its wake. Temperature never reaches the melting point so the metallurgical state of the material is less affected than during conventional fusion welding and, in the absence of a liquid phase, there can be no gas porosity or hot cracking.

The welds described in this paper were made on .25 in. thick 6061 aluminum using a .25 inch long pin tool with $.25 \times 20$ threads. The shoulder was .75 in. in diameter. The pin tool was made from quenched and tempered O-1 tool steel.

The movement of material around the nib is complicated and has been discussed by various authors $\left[{ }^{4},{ }^{5},{ }^{6}\right]$ who have used material markers to follow the flow. The flow model by Guerra [6] will be discussed and expanded in this paper. Fig. 1 shows a plan view of a welded piece cut at mid thickness. The weld proceeded from bottom to top in this figure. Curved striations which are spaced equal to the pitch (distance moved by the pin tool in each revolution) of the pin tool are easily seen $\left[^{7}\right]$.

The width of these striations is plotted in Fig. 2 for various rotational and traverse speeds of the pin tool. The data has been normalized by the diameter of the pin tool. It is believed that the striations are curved cylinders of material that have been shed off a region of material that rotates around the pin tool.

Fig. 3 shows a plan view of a pin tool that was frozen into the weld by abruptly stopping the weld. The faying surface at the top of the weld is curved around the rotation pin tool and the diameter of the annular region that rotates with the pin tool can been seen. This diameter is also plotted in Fig. 2. We note that the diameter of this "carousel" is less than the diameter of the weld path and becomes smaller as the weld becomes hotter (faster rotational speed and slower traverse speed). 
This paper will discuss these observations and interpret them in terms of a helical flow of material around the pin tool.

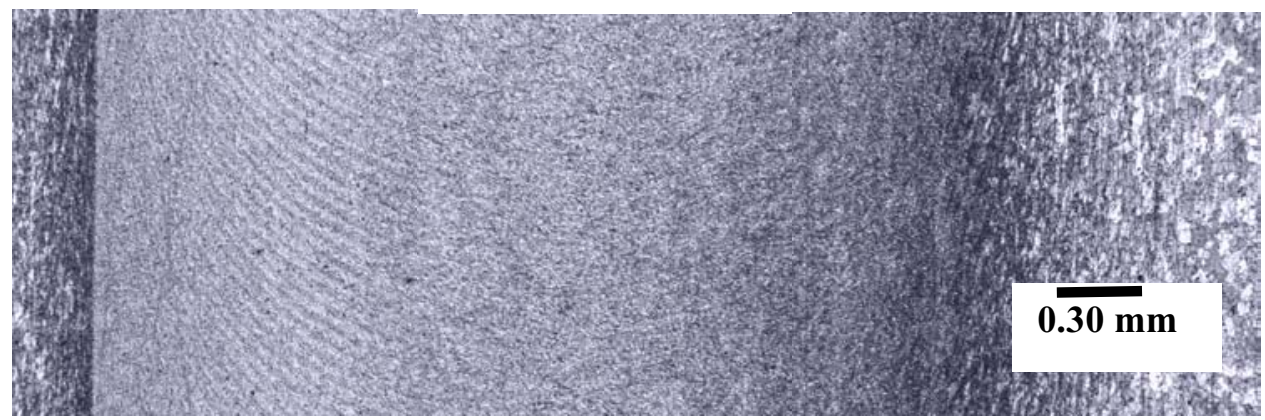

Fig. 1 showing weld path and striations at mid thickness.
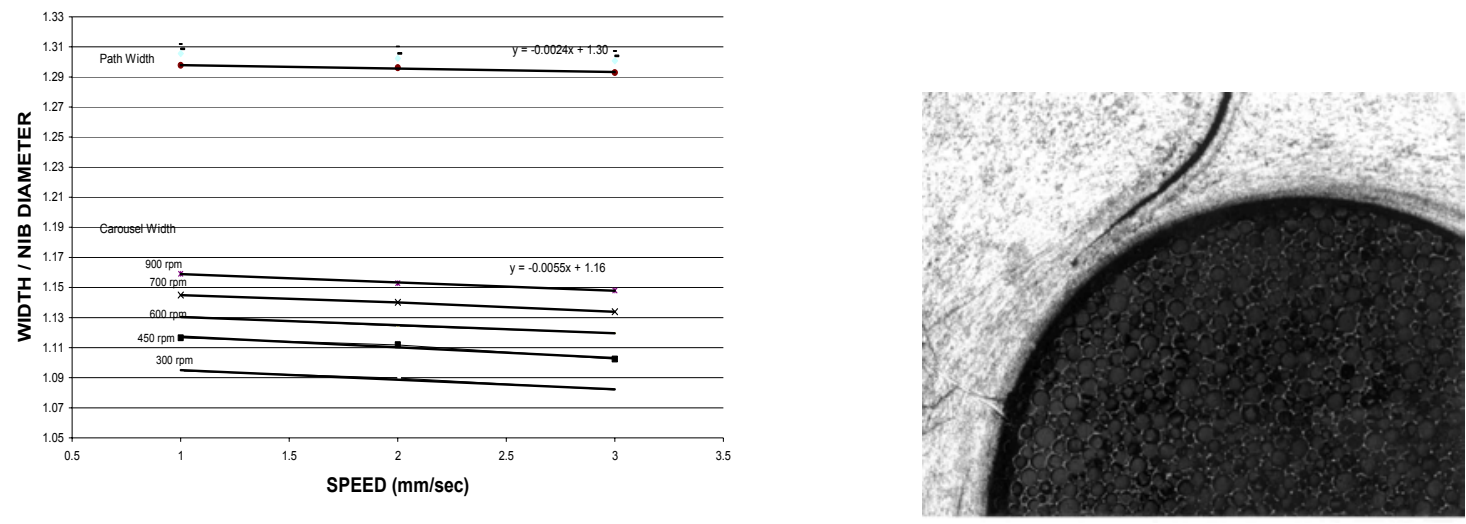

Fig. 2 (left) Weld path width and carousel width for various weld speeds and rotational velocities.

Fig. 3 (right) Curved faying surface ahead of the .25 inch diameter pin tool. Plan view at mid thickness.

${ }^{1}$ The Welding Institute, International Patent Application No. PCT/GH92102203.

${ }^{2}$ T. J. Lienert, W. L. Stellwag, B. B. Grimmett, R. W. Warke, "Friction Stir Welding Studies in Mild Steel", Welding Journal, January, 2003, p. 1-s.

${ }^{3}$ R. A. Prado, L. E. Murr, J.C. McClure, "Friction Stir Welding : A study of Tool Wear in Aluminum Alloy $6061+20 \%$ Al203", Friction Stir Welding and Processing, Ed., K. V. Jata, M. S. Mahoney, R. S. Mishra, S.L. Semiatin, and D .P. Field, TMS, 2001.

${ }^{4}$ K. Colligan "Material Flow Behavior during Friction Stir Welding of Aluminum", Welding Journal, July 1999, p. 229-s.

${ }^{5}$ T. U. Seidel, A. P. Renolds, "Visualization of Material Flow in AA2195 Friction stir Welds Using a Marker Insert Technique", Metallurgical and Materials Transactions, A, vol. 32A, November 2001, p. 2879.

${ }^{6}$ M. Guerra, J.C. McClure, A. C. Nunes, L. E. Murr, "Material Flow during Friction Stir Welding”, Friction Stir Welding and Processing, Ed., K. V. Jata, M. S. Mahoney, R. S. Mishra, S. L. Semiatin, and D. P. Field, TMS, 2001.

${ }^{7}$ K. N. Krishna, "On the Formation of Onion Rings in Friction Stir Welds", Materials Science and Engineering, A327 (2002), p. 256. 